\title{
En el momento oportuno y el lugar adecuado
}

\section{Dr. Enrique Pereira}

Presidente de la Asociación Argentina de Cirugía de la Mano y Reconstructiva del Miembro Superior

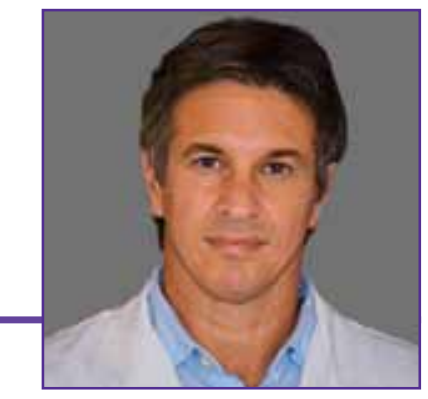

Desde su gestación en 1953, cuando se creó el Capítulo de Cirugía de la Mano en el seno de la Asociación Argentina de Ortopedia y Traumatología y, luego, a partir de su fundación en 1974, la finalidad de nuestra sociedad ha sido "estudiar, investigar, perfeccionar y difundir esta rama de la cirugía propendiendo al acercamiento científico con sociedades similares del país y del extranjero".

Escribir y publicar un trabajo científico constituye una de las labores académicas más relevantes y altruistas del investigador, permite difundir (del latín diffundre, extender por el espacio en todas las direcciones) el conocimiento médico.

El camino recorrido por nuestra asociación hasta el presente ha sido testigo no solo del legado transmitido de generación en generación a través de sus integrantes, sino también de una cantidad de valiosos aportes al desarrollo de la especialidad por parte de sus miembros. En ese recorrido, existieron, hasta la actualidad, distintos proyectos que, por diferentes razones y distintas circunstancias, no llegaron a poder encausar ese conocimiento en un órgano de difusión propio que pudiera sostenerse en el tiempo. Sin embargo, el legado referido seguramente sea hoy el artífice de la construcción de una pirámide sustentada en una amplia base de médicos entusiastas, dispuestos a dar un próximo paso y convertirse en protagonistas de un nuevo capítulo en la historia de nuestra sociedad, como es la producción de un suplemento de publicación perdurable, que lleve la impronta propia de sus integrantes.

La Revista de la Asociación Argentina de Ortopedia y Traumatología, nuestra sociedad madre, es referente histórica en Sudamérica, y avanza, con paso firme, en busca de la indexación. Contar con un mayor número de artículos originales es una premisa obligatoria en esa búsqueda, motivo por el cual la publicación de la AAOT requiere del aporte de todas sus sociedades huéspedes, y ofrece hoy un contexto sin precedentes para convertirse en vehículo de difusión del conocimiento de nuestros asociados.

El comienzo de cualquier empresa requiere de una voluntad inicial, dispuesta a mover una pieza. Ese primer movimiento, a veces, incluso sin motivo o finalidad concreta, en ocasiones, se transforma en un hecho trascendente que solo puede ser apreciado como tal con el paso del tiempo, con el matiz que agrega la distancia y adorna la historia.

Por eso, vaya el enorme reconocimiento a un gran grupo de personas que, habiendo aceptado este gran desafío, han aportado tiempo, energía, creatividad y trabajando en equipo, de manera seria y desinteresada, han permitido que aquel proyecto se convierta en realidad.

Ser puntual implica no llegar tarde o con demora, pero también supone no presentarse antes de tiempo, sino cuando las condiciones son propicias.

Este suplemento de la Asociación Argentina de Cirugía de la Mano no es producto del azar, ni llega de manera fortuita, sino que supone el inexorable desenlace de una búsqueda persistente y determinada de nuestra asociación, como concreción del trabajo previo que le ha dado sustento y que, como tal, se concreta en el momento de madurez.

Es decir, en el momento oportuno y el lugar adecuado. 